\title{
Precursores Coloniales de la Narrativa Hispanoamericana: José de Acosta o la Ficción como Biografía
}

Al estudiar la prosa de nuestros siglos formativos con frecuencia se olvida que las obras literarias tienen un tiempo y un lugar determinados. Tal olvido conduce a que pasen inadvertidas algunas relaciones, a veces decisivas, con las corrientes estéticas que prevalecian en el momento en que fueron creadas. $\mathrm{Y}$ a que al examinarlas fuera de su contex to histórico, se corra el riesgo de llegar a interpretaciones que opacan o contradicen su verdadero sentido. Es lo que ha ocurrido con algunos relatos que hasta ahora se han visto como simples biografías de oscuros personajes cuando son, creo yo, biografías noveladas en las que hay tanto o más de ficción que de biografía.

Fue autor de una de aquellas narraciones el historiador y naturalista jesuíta José de Acosta (1540-1600). Durante su larga estancia en el Perú conoció en el Colegio de la Compañia a un humilde hermano coadjutor llamado Bartolomé Lorenzo. Poco a poco fue descubriendo que aquel hermano en su juventud había vivido una serie de azarosas aventuras que le habian llevado de Portugal a las Antillas, y de allí a varios parajes de Tierra Firme, hasta hallar sosegado refugio en los claustros de la Orden en Lima. Acosta apunta brevemente los datos que a duras penas logra extraerle al reticente portugués. Con ellos compone luego un animado relato, lo titula Peregrinación de Bartolomé Lorenzo, y lo envìa a Roma, con carta fechada a 8 de mayo de 1586, a Claudio Acquaviva, prepósito general de la Compañía de Jesús ${ }^{1}$. Casi un siglo después, tomado al pie de la letra como auténtica biografía, fue incluído por Alonso de Andrade en uno de los tomos de Varones ilustres de la Compañia de Jesús ${ }^{2}$. En el siglo XIX Cesáreo Fernández Duro encontró una copia manuscrita en la Colección Muñoz, y dando por sentada la veracidad del documento, lo 
publicó en el Boletín de la Real Academia de la Historia ${ }^{3}$ Y Y como biografïa ha vuelto a aparecer en las Obras de Acosta, impresas en 1954.4 Ahora bien, ¿fueron reales las inusitadas aventuras de Lorenzo? ¿Ocurrieron todas y cada una de las peripecias tal como las cuenta Acosta? ¿Estuvo el protagonista en tantas tempestades, sanó de tantas enfermedades y sobrevivió a tan crueles aflicciones como las que allǐ se describen? ¿No pasarian los parcos informes orales de Lorenzo por un proceso que los amplifica, acomoda y ficcionaliza, tal vez con el fin de conferirles un ulterior sentido? Para hallar respuesta a estas y a otras cuestiones que el texto plantea, conviene que comencemos por situar al autor dentro de los parámetros artísticos e intelectuales de su época.

Acosta nace en 1540, en Medina del Campo, hijo de un próspero mercader de origen portugués. A los once años ingresa en el noviciado de la Compañía de Jesús y a los catorce hace sus primeros votos. De 1559 a 1567 estudia en Alcalá de Henares, entonces centro activísimo del humanismo español. Adquiere conocimientos de teología, filosofía y ciencias naturales. Posee, además, una mente ágil y precisa y demuestra un agudo sentido de observación. Esas dotes las empleará bien pronto: en 1571 pasa a la isla Española. A los pocos meses sigue viaje a Tierra Firme, y en 1572 llega al Perú. En el Perú ocupa cargos de predicador y de provincial. Estudia el clima, la flora, la fauna así como las costumbres de las principales civilizaciones indiggenas. Apoya sus opiniones en experiencias propias y no en la inoperante autoridad de filósofos antiguos. Y al regresar a Europa termina y en 1590 publica la Historia natural y moral de las Indias, a la cual debe su merecida fama de observador sagaz y de lúcido expositor 5 . Es, pues, en medio del trajín de sus múltiples ocupaciones que Acosta escribe, a modo de esparcimiento, la Peregrinación, y la envǐa, como obra de amena lectura, a su superior en Roma.

Atiéndase igualmente a que por aquellos años los humanistas españoles sentían franca hostilidad hacia las inverosimilitudes y los dudosos modelos de moralidad que aparecían en los libros de caballerías y otras obras de ficción. Como este asunto ha sido ampliamente estudiado ${ }^{6}$, baste con mencionar las opiniones de tres de los críticos más destacados de entonces. Juan Luis Vives, por ejemplo, se burla de los caballeros andantes que matan de un tirón a varios enemigos, y de aquel otro que, traspasado de seiscientas heridas, "al día siguiente, recobradas ya su salud y fuerzas, derriba en singular combate a dos gigantes". Y asimismo condena la facilidad con que princesas y doncellas se entregan a sus enamorados caballeros ${ }^{7}$. Juan 
de Valdés aconseja: "Los que escriben mentiras las deben escribir de suerte que se lleguen cuanto fuere posible a la verdad"8. El Dr. Alonso López Pinciano comenta: "Las ficciones que no tienen imitación y verosimilitud no son fábulas, sino disparates, como algunas de las que antiguamente se llamaron milesias, agora libros de caballerías, las cuales tienen acaescimientos fuera de toda buena imitación y semejanza a la verdad"9. Y concordando con estas opiniones, el propio Acosta declara que su Historia natural y moral de las Indias habrá de ser útil y de provecho, ya que no "es como gastar tiempo en leer las patrañas que fingen los libros de caballeria"10. La literatura a la que aspiraban había de ser, por consiguiente, verosïmil, y había de guardar "el decoro" y la "moralidad y buena doctrina", tal como convenía al propósito ético que impulsaba a todo el movimiento humanista.

El libro que vino a colmar las aspiraciones de aquellos doctos lectores fue la novela de viajes y aventuras titulada Historia etiópica de los amores de Teágenes y Cariclea. Compuesta en griego por Heliodoro hacia el siglo III o IV, sólo vino a conocerse en el siglo XVI, gracias al descubrimiento de un manuscrito en el saqueo de la biblioteca del rey Matías de Hungría. De ese manuscrito se publicaron ediciones y traducciones en Francia y en Holanda. Y en cuanto a España, precisamente en Alcalá apareció en 1587, la versión hecha por Fernando de Mena. La obra de Heliodoro quedaba, pues, muy ligada a las actividades de los humanistas de Alcalá11.

La novela que tanto interés habia despertado y que tan hondas huellas dejaría en las letras españolas ${ }^{12}$, tiene por marco geográfico a Egipto, Grecia, Etiopía y el Mar Mediterráneo. Sobre ese fondo, en parte real y en parte ficticio, se cruzan los destinos de dos castos amantes quienes padecen infinitos peligros e infortunios hasta que al fin, vencidas todas las adversidades, llegan a Etiopia, se revela el noble origen de Cariclea y termina la acción en feliz matrimonio. $Y$ lo que complacía a aquellos exigentes críticos es la constante invención de episodios, hábilmente hilvanados para mantener en suspenso la atención del lector, la riqueza y variedad de elementos narrativos $\mathrm{y}$, desde luego, el comportamiento ejemplar de los protagonistas y el tono edificante de la obra toda ${ }^{13}$.

Pues bien, es a esta luz que debemos examinar la Peregrinación. Por de pronto, ahora se ve con mayor claridad que al narrar Acosta la odisea de Bartolomé, lo que en el fondo se había propuesto era escribir una breve novela de viajes y aventuras. Para conferirle un tono de inobjetable verosimilitud escogió a un personaje apenas co- 
nocido, cuya insignificante existencia se prestaba para tejer en torno a ella cuantos lances concibiera la imaginación del autor ${ }^{14}$. Una vez elegido el protagonista, traslada la acción del Mediterráneo europeo al Mediterráneo americano, y de las trilladas tierras del Mundo Antiguo a las casi ignotas regiones del Mundo Nuevo. Ese cambio le permite desplegar a la vez sus conocimientos de geógrafo y su inventiva de novelista. Consigue así entreverar el plano de la realidad con el de la ficción y crear un ámbito en parte visto y en parte imaginado, en el que sagazmente combina lo cotidiano con lo insólito y lo real con lo fabuloso.

Esto se comprueba al verificar la doble óptica con que contempla los parajes por donde pasa Lorenzo. El itinerario de sus andanzas queda señalado con nombres de lugares conocidos. Parte de Portugal por el puerto de Villanueva, recala en las Islas Canarias, prosigue a Cabo Verde, cruza el Atlántico, llega a la isla Española y desembarca en Montecristi. Continúa por tierra a Concepción de la Vega y luego a Santo Domingo. Vuelve sus pasos al interior, sigue hasta La Yaguana, y de alli cruza a Jamaica. De Jamaica sale hacia Tierra Firme, llega a Nombre de Dios y pasa a Panamá. Corre nuevas aventuras por la costa de Veragua, regresa a Panamá y se embarca rumbo al Perú. Baja en la isla de Cocos, retorna al continente y continúa el viaje pasando por Puerto Viejo, Jipijapa, Guayaquil, Loja, Piura, Trujillo, Chancay y la Barranca hasta que llega a Lima.

Si los hitos de la ruta quedan marcados con nombres de lugares reales, no ocurre lo mismo con la visión que Acosta nos ofrece de la naturaleza. El autor contempla el paisaje con una pupila ficcionalizadora que lo distiende, magnifica y torna pavoroso. La naturaleza resulta asĩ alucinante y torturadora. En La Española las sierras son "fragosisimas", los caminos "en extremo dificultosos", los ríos "grandes y de furiosas corrientes", las peñas "inaccesibles", "inmensos los pantanos" e "infinitos" los mosquitos "que muerden cruelísimamente hasta poner a una persona como llagada del mal de San Lázaro". En Jamaica se pierde entre "grandes peñas muy secas y sin refrigerio alguno". Súbitamente llega, por contraste, a "un valle muy fresco y fértil". Pero pronto entra "en una montaña muy cerrada y estrecha", incendia un helechal donde está a punto de morir abrasado, se pierde en un monte muy espeso, y "hallándose tristísimo por no ver cielo ni tierra, ni saber qué camino llevaba para salir de aquella tan terrible montaña", sube trabajosamente a un árbol altísimo, sólo para encontrar, anidada en el tope, "una fiera y disforme culebra". Y así sucesivamente, incrementándose las penalidades al internarse en 
Tierra Firme, hallarse en medio de un espantoso terremoto "que duró continuamente diez y ocho días 15 , y toparse con tigres, caimanes y otras fieras que más parecen proceder de un bestiario medieval que de una geografía americana. La imagen que nos deja es, desde luego, la de la selva selvaggia de Dante.

$\mathrm{Nada}$ de esto ocurre por azar, sino por designio. Acosta ha querido conferirle a la Peregrinación un sentido alegórico. A ese efecto intensifica las penalidades que sufre Lorenzo, de modo que correspondan a las penitencias a que se somete el cristiano en busca de su salvación. Abordemos este aspecto del relato desde el principio. El peregrino emprende el viaje para evitar el castigo que recibiría "por una desgracia en que un hombre fue afrentado" y que él no habia cometido. O sea, en el plano alegórico, para redimirse del pecado original. En Cabo Verde enferma gravemente. Estando "dejado de todos, sin esperanza de vida", entra en su aposento una mujer, le ordena que beba mucha agua, y con esto al otro día se levantó curado. Esa mujer, de quien "no se sabe quien fuese", y a quien ni "antes ni después nunca la vio", representa, por supuesto, a la Virgen Maria, y el agua salvadora las aguas del bautismo. Hecho prisionero frente a Montecristi por piratas luteranos, estos se mofan de él "levantando en alto pedazos de cazabe, haciendo burla del sacrosanto misterio de la hostia". Por haberle hallado un rosario, "le dieron muchos golpes y puntillazos". Y estaban a punto de matarlo cuando llega "un capitán principal, a quien todos obedecìan" y le salva la vida. Esta peripecia, de palmario sentido alusivo, se resuelve por milagrosa intervención divina. En la Española vuelve a enfermar gravemente. "En esta enfermedad", puntualiza Acosta, "le dio Nuestro Señor aborrecimiento de hacienda y deseos de soledad". O sea, otro paso hacia el voto de pobreza y la vida contemplativa. Un día sale a cazar puercos y de pronto ve ante sí "un bravísimo toro ... que se vino como un león para Lorenzo". En tal peligro, "ayudado de Nuestro Señor", acierta a clavarle una desjarretadera por la espaldilla, "dejándolo muerto a sus pies". La victoria sobre el toro bien pudiera interpretarse como el triunfo del hombre sobre la violencia de las pasiones. Otra vez, "pretendiendo romper por un monte muy cerrado, se recostó sobre un gran tronco de árbol que estaba atravesado en el camino, y después reconoció que era una grandísima culebra". Culebras de tal tamaño no las hay en las Antillas. De modo que la insidiosa serpiente que Bartolomé reconoció es otra encarnación del demonio, siempre acechante y siempre pronto a engañar a la prole de Eva. Parte luego con un compañero hacia unas minas. Se pierden y 
padecen grandes mortificaciones. Al cabo de cinco meses "los trujo la Providencia divina a vista de unas vacas, y siguiendo el rastro de ellas dieron en unos vaqueros" que los encaminaron a Santiago. Cinco meses para hallar el camino en la Española es, desde luego, patente hipérbole para encarecer los padecimientos que sufre Bartolomé. En fin, sale de nuevo y vuelve a perderse. Llueve torrencialmente. Y él iba descalzo, cruzando "lagunas y pantanos por donde le era forzoso marchar días y noches... sin ver donde ponỉa los pies, que a cada paso los asentaba sobre abrojos y espinas". Estas inhóspitas paludes distan de ser los placenteros valles que contemplaron absortos Colón y Las Casas. Y representan otro doloroso tramo del via crucis del peregrino. Encuentra luego a un caballero que lo envia a Jamaica con carta "a su mujer y suegro para que allì le acomoden y regalen". Es bien recibido, pero a los pocos dỉas, "pareciéndole que era mozo y que aquella señora, aunque muy honrada y virtuosa, en fin era mujer, acordó dejar la posada y quitar al demonio la ocasión de hacer de las suyas". O sea, para apartarse de la tentación de la carne.

Los pasajes comentados proceden de las primeras cuatro páginas de las veinte que forman la edición por la cual cito. Para no abrumar al lector con prolijos pormenores escogeré de las restantes sólo tres episodios que ejemplifiquen la continuidad del proceso alegórico. El primero pasa en la costa del Mar del Sur. Lorenzo empieza a llevar vida de ermitaño.

Un dỉa, bajando a la playa del mar a coger algunos cangrejos para comer, cuando menos pensó, volvió el rostro y vio cerca de sĩ un fiero tigre. Santiguose y dijo: "Jesús sea conmigo". Y volviéndose a Nuestro Señor le dijo en su corazón: "Señor, si yo nacĩ para ser comido de esta fiera, cúmplase tu voluntad". (314)

Si esta escena de pronto evoca a los mártires devorados por las fieras del circo, la plegaria, musitada fervorosamente, sigue de cerca las últimas palabras de Cristo en la cruz.

Por otra parte, desde el punto de vista artǐstico cabe añadir que Acosta no se detiene en lo meramente alegórico. Con certero sentido de buen narrador pasa a describir la consiguiente lucha, que refiere asî:

Notó Lorenzo que bajaban los tigres a la playa del mar a pelear con los caimanes y comerlos, y es una de las más fuertes batallas que hay entre las fieras, porque el caimán 
tiene gran fuerza y aprieta fuertemente al tigre con la cola, y éste con extraña ligereza entra y sale y acomete a su contrario, hiriéndole siempre en estos encuentros, que al cabo viene a quedar rendido y muerto el caimán, de cuya sangre se harta hasta más no poder. (314)

Pura pedantería serỉa, a estas alturas, dudar que los tigres se hartasen de la sangre de los caimanes, y que los caimanes apretasen con la cola en lugar de golpear con ella. ¿No creyó Colón que los manaties eran sirenas? Para lectores acostumbrados a los endriagos y sierpes de los libros de caballerías, todo era admisible. De modo que la escena que contemplan las asombradas pupilas del ermitaño es algo más que una improbable lucha entre cuadrúpedos y reptiles: se asemeja a un fabuloso y mortal combate entre hipogrifos y dragones.

El segundo episodio sucede en una isla cerca de Nicaragua. Los que desembarcan con Lorenzo encuentran allï a más de cuarenta hombres que fabricaban una nao. Pronto hay pendencia entre unos y otros. Pasan de las palabras a las armas. Acude el peregrino a socorrer a un herido, y "a este tiempo le tiraron un dardo, que hirió a Lorenzo por las costillas del lado derecho, metiendo el hierro en el cuerpo hasta apuntar al otro lado". (315) El talento descriptivo de Acosta se explaya luego en pormenores de la descomunal herida y de las penosas curaciones. Pero tras la plasticidad de las figuras y el dramatismo de las peripecias, de nuevo aparece el sentido alegórico: Lorenzo ha sido herido igual que Cristo en la cruz.

El tercero ocurre en una de las últimas jornadas de la Peregrinación. Al regreso de una "entrada a indios", los soldados y sus prisioneros habian de cruzar por

un paso muy peligroso entre una altǐsima roca y la mar, la cual en tiempo de crecientes cubría todo el camino y batía en la roca, y así era necesario pasar con la menguante para no ahogarse.

Cuando llegó allí la compañia, era ya cerca de ponerse el sol, y la mar iba corriendo muy apriesa y el camino era un lodazal ... Una india, embarazada con esta priesa, soltó un hijo que llevaba en los brazos, y dejole en aquella peña llorando y gimiendo...

Cuando llegó Lorenzo (que iba en la retaguardia aquel dia) y vio aquella criatura sola y llorando, que seria de seis años, y que de ahí a poco se le había de llevar la mar, moviole la compasión y sin atender a su mesmo peligro, se 
ató el arcabuz a las espaldas y tomó en brazos aquel niño, y así pasó todo el pantano. (318)

Tras el interés narrativo y el colorido de las descripciones se trasluce otra vez la intención alegórica. Ha habido, en primer lugar, una gradual progresión. De las tres virtudes teologales, en las primeras peripecias se acentuaba la fe del joven viajero: fe que le salva de graves enfermedades y peligros. En las siguientes se subraya principalmente la esperanza: la constante esperanza de llegar a Lima. En las últimas lo que sobresale es la caridad: piadosa caridad hacia un hombre que yace herido; tierna caridad hacia un niño que llora abandonado. Su comportamiento en este pasaje le lleva, además, a realizar la misma hazaña en la que San Cristóbal cruza una impetuosa corriente portando en sus hombros al niño Jesús. Alcanzado este punto de la Peregrinación, sólo restaba al hermano Bartolomé hacer precisamente lo que añade Acosta: se retira a un monte por cuarenta días-como Cristo-y al salir ingresa en la Orden para completar el estadio final de su salvación.

Expuesto sumariamente el plano alegórico, es fácil discernir lo demás. Acosta emplea la estructura biográfica para armar una breve novela de viajes y aventuras. Con ese propósito en mente, manipula cada uno de los lances de manera que contribuyan al interés de una trama que constantemente oscila entre recios peligros e inesperadas soluciones. Para seguir manteniendo en suspenso el ánimo del lector, los enlaza como si fuesen las cuentas de un rosario de tribulaciones y victorias. A fin de conferir al relato el ulterior sentido edificante, tan grato a los críticos de la época, hace del protagonista un dechado de sencillez, humildad y devoción cristianas. Y se vale del conjunto para postular el mensaje de su empeño misionero: si todos los caminos llevan a Roma, los de América, tan agrestes y peligrosos, también son propicios para la peregrinación que conduce a la salvación y aún a la santidad 16 .

Dentro del proceso ficcionalizador se percibe, además, un desdoblamiento del autor. El peregrino portugués y el humanista de Alcalá-también de ascendencia portuguesa-han seguido los mismos rumbos desde la partida de la Penìnsula hasta el encuentro de ambos en el convento de Lima. Las aventuras que Acosta le atribuye a Lorenzo son, pues, una proyección imaginativa de las que pudieran haber sido sus propias andanzas. De modo que el autor deviene así relator, testigo y protagonista de la doble peregrinación: la real y la imaginaria. 
Acosta quiere que su obra, a más de entretenida y edificante, resulte útil y provechosa 17 . Y en esta ocasión opta por destacar el estado social de las Indias, y sobre todo exponer las iniquidades que seguían cometiéndose contra la dignidad del ser humano.

Iniquidades, primero, contra el indiggena. Para ejemplarizarlas comienza por un encuentro aislado pero sumamente revelador. Perdido el protagonista en lo más fragoso de la isla de Jamaica, halla un bohĩo, y en él a "un indio muy viejo, solo, sin humana criatura, el cual en años pasados, huyendo de la opresión y malos tratos de los españoles, escogió esconderse en aquellos montes, donde jamás pudiera ser hallado". (308) Obsérvese que aquí es el narrador omnisciente quien subraya: "solo, sin humana criatura", o sea, reducido al estado de bestia perseguida. No hay por qué dudar que Acosta, en su estudiosa juventud, se enterase de las peregrinaciones, contiendas y padecimientos de aquel otro Bartolomé que también abandonó hacienda y poder en las Antillas para vestir un hábito monacal y convertirse en dolido defensor de la dignidad del indio. De todos modos, la postura moral del autor coincide con la de Las Casas. Y esa postura se hace aún más elocuente cuando, ya en Tierra Firme, relata una cacerỉa de indïgenas a la que entonces se llamaba, eufemisticamente, "entrada a indios". Lorenzo no quiere participar en tal expedición, "diciendo que él no había de ir a quitar a nadie su libertad, y que aquellos indios, contra quien se encaminaba esa jornada, no le habïan a él ofendido para que los fuese a guerrear". (317) Un fraile le advierte que "si no lo hacía, que sin duda le urdirian alguna maraña con que ahorcarle, y que en aquel viaje vería cómo se hacía la conquista". Y lo que vio fue la injustificada agresión y captura de un grupo de indígenas, la manera en que "a ellos y a sus mujeres e hijos los trujeron a Puerto Viejo, metiéndolos en colleras porque no se huyesen", los sufrimientos de aquella jornada, que culmina con el episodio del niño abandonado, y el repartimiento de los prisioneros cuando llegan al pueblo. $Y$ es ahora el narrador testigo el que afirma que "si le costare la vida, no volvería a hacer otra entrada, que no hallaba por donde era razón ir a quitar a otros su casa y libertad, no habiendo recibido de ellos agravio". (318)

$\mathrm{E}$ iniquidades, también, contra el negro. Es ya un duro comentario que al principio del viaje apunte secamente que en Cabo Verde "habían de comprar cantidad de negros para trocarlos por cueros" en Santo Domingo. De nuevo hombres deshumanizados, esta vez convertidos en patética mercancía. $\mathrm{Y}$ siguen apareciendo negros infelices a lo largo de toda la Peregrinación: conduciendo recuas en la Española, 
cuidando ganado en Jamaica, cortando madera o lavando oro en Tierra Firme. Algunos de estos se escapan y los vuelven a apresar. Otros, más afortunados, huyen, fundan palenques y defienden gallardamente su libertad. Son los llamados "cimarrones". Lorenzo oye decir que estos roban y matan a los viajeros. Ahora bien, al ir él y otro compañero, camino a Panamá,

cerca de la venta de La Quebrada les salieron los negros con lanzas y ballestas... Lorenzo se llegó a ellos sin miedo, no sabiendo que aquellos eran los cimarrones, y con mucho contento les preguntó el camino. $\mathrm{Y}$ diciendo ellos qué llevaba, sacó de la capilla de su capa bizcocho y convidó con él al más viejo, que era el capitán. Y los negros, vista su simplicidad, se rieron y hablaron entre sì su jerigonza, y no sólo no le hicieron mal, pero le ofrecieron del pescado que traǐan ... Y le dieron que le guiasen dos negros valientes para pasarle el rǐo, que venỉa crecidísimo. (311)

El generoso comportamiento de estos hombres habla por sí solo. Pero Acosta, para recalcar el propósito aleccionador de lo sucedido, agrega este comentario:

De modo que los que a otros suelen saltear y quitar la vida, a Lorenzo, por su buena fe, se la dieron, y asǐ se maravillaban después los españoles de la humanidad que con ellos habian usado, y él se maravillaba también que aquellos fuesen los cimarrones tan temidos. (311)

Otro aspecto de la Peregrinación que no debe pasar inadvertido es la postura que Acosta adopta ante el lenguaje. Como buen humanista al fin, sin duda había reflexionado sobre la naturaleza de la lengua española, su genio propio y sus recursos expresivos ${ }^{18}$. Pero no se detuvo ahí. Su experiencia americana le llevó a comprobar que el idioma de Castilla resultaba inadecuado para nombrar las nuevas realidades de las Indias. Acosta se siente impelido a enriquecerlo para que sirva de idóneo instrumento de expresión. De modo que en sólo unas veinte páginas de texto incluye otros tantos americanismos, algunos de los cuales repite varias veces. Para tener una rápida idea sirva la siguiente lista de los principales: arcabuco, bejuco, bijao, bohio, cabuya, caimán, canoa, caribe, cazabe, ceiba, cimarrón, curaca, galpón, guayaba, iguana, jobo, maiz, mamey, nigua y sabana.

Observemos ahora sus procedimientos al incorporarlas al texto. El primero de los americanismos que emplea es un préstamo del 
taǐno, aprendido por los españoles desde los primeros momentos de la conquista: cazabe. Para 1586 el uso de esta voz estaba tan generalizado que no cree necesario explicar su sentido o describir la forma circular y el escaso espesor de la torta. Simplemente alude a esas cualidades al referir que los piratas luteranos se mofaban de Lorenzo "levantando en alto pedazos de cazabe, haciendo burla del sacrosanto misterio de la hostia". Y cuando vuelve a usar el término más adelante, de nuevo lo emplea sin dar explicación alguna: "una fragata ... que enviaba con cazabe a Tierra Firme". Lo mismo ocurre cuando da por sentado que el lector está familiarizado con el término o que fácilmente puede deducir el sentido del contexto en que aparece. Asǐ lo hace, por ejemplo, con los americanismos guayabas, maiz, iguanas, cabuya, caimanes, canoas y bejucos.

Procede de manera muy diferente cuando piensa que debe esclarecer el significado o cuando quiere destacar alguna cualidad pintoresca, sorprendente o esencial del término en cuentión. Entonces recurre, en primer lugar, a la sencilla fórmula de mencionarlo junto con un equivalente, más o menos aproximado, del español de la península. Tenemos asî: "andaba por una sabana o prado", "descubrieron un bohio o rancho", "entráronse por el monte, que allá dicen. arcabuco". Y cuando no existe tal equivalente, entonces procede a una descripción más detallada agregando, en frases sucesivas, los aspectos definidores. Consigna entonces que halló "muchos mameyes, que es fruta estimada en las Indias, que tiene el tamaño y hechura mayor que grandes melocotones, y tiene dos huesos grandes dentro". O esta otra: "Descubrió un árbol altísimo, que era de la casta de las ceibas, que usan los indios para hacer canoas, que son barcos de una pieza, cavados como artesas". Y un ejemplo más: "Daba en aquella tierra una enfermedad de unos insectillos, que se metlan por la carne sin sentir, que llaman niguas, y se van hinchando y engrosando más que un dedo, y estos causan gran dolor".

De la considerable cantidad de americanismos que incorpora puede verse que Acosta acoge en su texto términos relacionados no sólo con la flora, la fauna y la topografía, sino también con artefactos, productos alimenticios, hábitos y costumbres y organización social. Era un mundo, vasto y complejo, el que había de ser captado por medio del lenguaje. Al peligro de una lengua estática Acosta opone el ideal de un idioma dinámico, abarcador y preciso. $\mathrm{Y}$ al ponerlo en práctica logra una creación verbal de extraordinario alcance: con varios siglos de adelanto lleva a cabo la apertura lingüìstica que caracteriza a los mejores narradores hispanoamericanos de nuestros dỉas. 
El proceso de fabulación, el sentido alegórico, los comentarios sociales y la praxis lingüística no deben hacernos perder de vista que la Peregrinación de Bartolomé Lorenzo tiene también un propósito artístico. Hay unidad y coherencia en los episodios. Las acciones del protagonista son consistentes con su carácter. Tras el firme manejo de una tersa prosa renacentista se advierten toques de comicidad e ironía, finos efectos cromáticos y rasgos de energìa y vivacidad. Todo eso, desde luego, inscrito en la superficie del texto. Y en el fondo, algo de mayor trascendencia: esta obra es un relato desgajado de la épica de la conquista. El peregrino sigue la misma ruta que transitaron los soldados de Pizarro: las Antillas, Panamá, el Perú. Pero a Lorenzo le guĩa otro objetivo. Pizarro y los suyos se abrieron paso, a sangre y fuego, para adquirir riquezas que a menudo pagaron con la vida. Lorenzo se abre paso, con actos de humildad y devoción, para acumular méritos que le ganen la vida eterna. La conquista militar ha sido desplazada por la conquista espiritual. Los tiempos, en verdad, ya eran otros.

En resumen, se sabìa que Acosta fue observador sagaz de la flora y la fauna americanas, que se explicó lúcidamente la llegada del hombre a este hemisferio, y que se percató de la imperiosa necesidad de estudiar y comprender las culturas indígenas. Lo que no se sabía es que, situado estrictamente dentro de las corrientes intelectuales y artǐsticas de su época, escribió un relato novelesco con algo de biografía real y mucho de los imaginario y fabuloso. En esa ficción renueva un modelo narrativo que se proyecta sobre los siglos venideros, en especial en la todavia mal entendida novela de viajes y aventuras escrita por otro humanista de extracción jesuítica: los Infortunios de Alonso Ramirez, de Carlos de Sigüenza y Góngora ${ }^{19}$. Anticipa el recurso de tejer el tapiz de un relato ficticio en torno a un personaje que realmente existió, como harán luego Borges y Carpentier. Realiza un desplazamiento en el espacio que le permite crear un ambiente americano, alucinante y hostil, que prefigura el de muchas novelas modernas; el de La Vorágine, por ejemplo, y el de otras más recientes, como las continuas lluvias y otras extrañas calamidades que asolaron a Macondo en Cien años de soledad. Aborda situaciones en las que actualiza la perenne crítica social iniciada por Montesinos y Las Casas. Asume inequivocas posturas mediante las cuales echa los cimientos de la literatura indianista y negrista. Deja preclaro ejemplo de cómo situarnos ante el español que hablamos en América. Dramatiza la ya visible fisura entre el mundo cultural que dejó allá y el que halló acá 20 . Y con esos elementos postula una radical respuesta a la 
cuestión, tan debatida a partir del siglo XIX, sobre la singularidad y autoctonía de la literatura escrita en el Nuevo Mundo. Razones todas por las cuales merece Acosta un lugar muy destacado entre los precursores coloniales de la narrativa hispanoamericana.

Yale University

JOSÉ JUAN ARROM

\section{NOTAS}

1. El propio Acosta suministra estos informes en la carta dedicatoria que acompaña a la Peregrinación.

2. Alonso de Andrade, S. J., Varones ilustres de la Compañía de Jesús, V, Madrid, 1666, págs. 759-783. En la edición moderna, IV, Bilbao, 1889, págs. 18-47. Esta edición es la más completa y fidedigna de todas.

3. Cesáreo Fernández Duro, "Peregrinación por las Indias Occidentales en el siglo XVI", Boletín de la Real Academia de la Historia, Madrid, XXXV, 1899, 226-257. Del cotejo con la edición anterior se deduce que el copista se tomó la libertad de resumir y modificar numerosos párrafos. Se trata, pues, de una versión estragada y poco confiable.

4. Obras del P. José de Acosta de la Compañía de Jesús. Estudio preliminar y edición del P. Francisco Mateos. Madrid, Ediciones Atlas, 1954, págs. 304-320. Citaré por esta edición, ya que es la más asequible, y consignaré las páginas en paréntesis a continuación del trozo citado. Al cotejar el tex to de ésta con el del P. Andrade he hallado leves omisiones y algunos errores de transcripción que, desde luego, he restituído o corregido, según sea el caso.

5. Sobre la vida y la trascendencia de la obra de Acosta véanse, a más del citado estudio preliminar del P. Mateos, los trabajos siguientes: León Lopetegui, S. J., El padre José de Acosta, S. J., y las misiones, Madrid, Consejo Superior de Investigaciones Científicas, 1942, y José Rodrĭguez Carracido, El P. José de Acosta y su importancia en la literatura científica española, Madrid, Sucesores de Ribadeneyra, 1899,

6. Especialmente por Marcel Bataillon, en su fundamental Erasmo $y$ España, estudios sobre la historia espiritual del siglo XVT, Vol. I, México, Fondo de Cultura Económica, 1950, págs. 210 y sigs. Hay edición más reciente.

7. Ibid., pág. 216 .

8. Ibid., pág. 220 .

9. Alonso López Pinciano, Filosofía antigua poética, Madrid, 1596, Episstola V. En la moderna edición de Alfredo Carballo Picazo, II, Madrid, 1953, pág. 8.

10. Historia natural y moral de las Indias, Libro quinto, cap. XXXI. Lo citado aparece en el siguiente contexto: "Baste lo referido para entender el cuidado que los indios ponian en servir y honrar a sus idolos... porque contar por entero lo que en esto hay es cosa infinita y de poco provecho; y aún en lo referido podrá parecer a algunos que lo hay muy poco o ninguno, y que es como 
gastar tiempo en leer las patrañas que fingen los libros de caballerǐa; pero estos, si lo consideran bien, hallarán ser muy diferente negocio, y que puede ser útil para muchas cosas tener noticia de los ritos y ceremonias que usaron los indios". (En la edición de Madrid, 1954, pág. 181). Sobre la necesidad de que la obra sea útil y de provecho volveremos más adelante.

11. Historia etiópica de los amores de Teágenes y Cariclea, traducción en romance por Fernando de Mena. Edición y prólogo de Francisco López Estrada, Madrid, Aldus, 1954.

La primera edición del texto griego apareció en Basilea en 1534; la primera versión al francés la hizo Jacobo de Amyot, que la dio a la imprenta en 1547. A vista de esa versión la tradujo al español un "secreto amigo de su patria", traducción que se imprimió en Amsterdam en 1554. Acosta bien pudo haber manejado alguna de estas ediciones.

12. Entre las numerosas novelas, comedias, poemas y otras creaciones analizadas por López Estrada se halla nada menos que la de otro insigne alcalaĭno: los Trabajos de Persiles y Segismunda, novela que el propio Cervantes creyó que habrìa de ser la mejor de todas sus obras.

13. Véase el mencionado estudio de López Estrada.

14. Con respecto a la cuestión de la verosimilitud, López Pinciano desarolla un argumento que bien puede aplicarse al relato de Acosta: "Por ventura hay alguna historia antigua de Grecia que os diga que Teágenes no fue de sangre de Pirro, y alguna de Etiopia que Cariclea no fue hija de Hidaspes y Persina, reyes de Etiopìa? Yo quiero que sea ficción, como decìs, y yo creo más: como no se puede averiguar, no hay por qué condenar al tal fundamento como fingido; y en esto, como en lo demás, fue prudentǐsimo Heliodoro, que puso reyes de tierra incógnita, y de quienes se puede mal averiguar la verdad o falsedad". (Episstola XI. En la ed. de Carballo Picazo, vol. III, págs. 194-195).

En el caso de Lorenzo, Acosta lo menciona como personaje real y fidedigno en la Historia natural y moral de las Indias (libro cuarto, cap. XXX). El padre Andrade añade a la presunta biografía un elogio en el cual consigna que Lorenzo entró en la Orden el 8 de octubre de 1577, estuvo nueve años en el colegio de Lima, quince en la granja que la Compañía tenỉa, y "fue su santa muerte en el mes de setiembre de mil y seiscientos, a los setenta de su edad y veinte y cuatro de Compañà". (Ob. cit., págs. 45 y 47). Nada de lo cual resta valor novelístico a la ficcionalización de la biografĩa.

15. La descripción del terremoto permite una puntual constatación del proceso ficcionalizador al que Acosta somete el paisaje. El autor traslada a las páginas de la Peregrinación el recuerdo de otro terremoto que, según le contaron, habia ocurrido en Chile. Dice en la Historia natural: "En la costa de Chile, no me acuerdo qué año, hubo uno terribilísimo, que trastornó montes enteros, y cerró con ellos la corriente a los rios, y los hizo lagunas, y derribó pueblos, y mató cantidad de hombres, y hizo... otras cosas semejantes de mucho espanto". (Lib. III, cap. XXI, pág. 87). La versión en la Peregrinación, adaptada a las circunstancias de Lorenzo, dice: "Sucedió un temblor de tierra espantoso, que duró continuamente 18 días, con que se trastornaron muchos cerros y apare- 
cieron lagunas donde se cerraba la corriente de los rios; y como toda aquella tierra era montaña espesisima de muy altos árboles, fue grande el espanto que causó la multitud de ellos que cayeron con la violencia del temblor". (313)

16. Y tenǐa razón Acosta: por aquellos años el Nuevo Mundo dio a la cristiandad un notable número de santos, unos venidos de España, otros nacidos en América. En orden cronológico son: Santo Toribio de Mogrovejo (1534-1606), San Francisco Solano (1549-1610), San Martín de Porres (1569-1639), San Felipe de Jesús (1572? -1597), San Pedro Claver (1580-1654) y Santa Rosa de Lima (1586-1617).

17. En cuanto al propósito, explícitamente formulado, de que la obra fuese útil y provechosa, véase lo citado en la nota 10 . También el libro séptimo, cap. I.

18. Sobre la postura de los humanistas ante las modernas lenguas europeas, véase el prólogo a mi edición de la Historia de la invención de las Indias, de Hernán Pérez de Oliva, Bogotá, Instituto Caro y Cuervo, 1965, págs. 23-25.

19. En 1963 aclaré la indole novelística de los Infortunios de Alonso Ramirez, relato que comienza con dejos de novela picaresca, continúa como novela de viajes y aventuras y resulta, desde luego, otra biografía ficcionalizada. Véase mi Esquema generacional de las letras hispanoamericanas, Bogotá, Instituto Caro y Cuervo, 1963; 2a. ed., 1977, pág. 85.

20. Acosta fue de los primeros en observar rasgos diferenciadores entre americanos y peninsulares. Sobre este asunto puede consultarse "Criollo: definición y matices de un concepto: en mi Certidumbre de América, 2a. ed., aumentada, Madrid, Editorial Gredos, 1971, págs 11-26. 
